\title{
Factors associated to populations' behaviour towards cholera in Cotonou (Benin)
}

\author{
Moussiliou N. PARAÏSO ${ }^{1 *}$, Rhéda ADEKPEDJOU ${ }^{2}$, Joseph FLÉNON ${ }^{2}$ and \\ Michel MAKOUTODÉ ${ }^{1}$
}

\author{
${ }^{1}$ Regional Institute of Public Health, Ouidah,University of Abomey-Calavi, Benin. \\ ${ }^{2}$ Faculty of Health Sciences of Cotonou, University of Abomey-Calavi, Benin. \\ *Corresponding author, E-mail: mparaiso@irsp-ouidah.org
}

\begin{abstract}
A disease related to hygiene, cholera is an affection which rages for centuries in the endemic states with epidemic hatchings worldwide. Benin, in particular in its littoral region, is not spared by the disease. The objective of this study was to determine the behavioural factors of the bad hygiene practice of the populations from Vossa-Kpodji in Cotonou towards the cholera. The study was cross-sectional, descriptive and with an analytical aim. A questionnaire was administered to all adults of 18 years and older. An individual was considered as having bad practices when his/her score was less than 14 points according to the present criteria. Of the 408 respondents, $91.4 \%$ had bad hygiene practices. The socio-demographic variable associated with poor practices, was marital status $(\mathrm{p}=0.04)$. The proportion of subjects with bad practices was higher among single $(97.3 \%)$. The level of knowledge of hygiene was significantly related to hygiene practices $(\mathrm{p}=0.03)$. Latrine coverage was low $(36.8 \%)$ and strongly linked to bad hygiene practices $(p<0.0001)$. The Ministry of Health should assist people for the achievement and perpetuation of public and household latrines and develop a sanitary program that takes into account peripheral areas of Cotonou.

(c) 2015 International Formulae Group. All rights reserved.
\end{abstract}

Keywords: Associated factors, hygiene, cholera, Benin.

\section{INTRODUCTION}

Cholera is endemic epidemic acute infectious disease caused by Vibrio cholerae, characterized by copious, painless, watery diarrhoea that can quickly lead to severe dehydration and death without prompt treatment (Fattorousso et al., 2004). The main reservoirs of the infectious agent are humans and aquatic environments (Tabarly, 2012). Since the first outbreak of cholera in 1817, several pandemics followed one another over the centuries. The number of cases reported to the World Health Organization (WHO) keeps growing. In 2011, 58 countries reported 589 854 cases and 7816 deaths. Numerous cases are not listed because of the limitations of surveillance systems and fear of sanctions restricting travel and trade. It is estimated that the real balance sheet of the disease amounts from 3 to 5 million cases and 100000 to 120 000 deaths a year (WHO, 2014). Since 2000, the incidence of cholera has steadily increased, and overall in 2010, the cumulative number of cases increased by $43 \%$ compared 
to 2009 and by $130 \%$ compared to 2000 (WHO, 2011). Africa is significantly affected by the epidemic. Indeed, among recent major outbreaks, we note Zimbabwe's epidemic with 98591 cases and about 4000 deaths between 2008 and 2009. The Lake Chad Basin (Niger, Nigeria, Chad, and Cameroon) also paid a heavy price with 142727 cases and 5179 deaths recorded between 2009 and 2011. In 2011 and 2012, a major epidemic raged along the Gulf of Guinea, the most affected countries were Ghana, Sierra Leone and Guinea. In May 2011, the World Health Assembly recognized that the re-emergence of cholera was a major public health issue (WHO, 2011). In Benin, from 2009 to 2012 there were a cumulative total of 2448 cases and 15 deaths. Cotonou, at the littoral, is one of the most affected areas of the country with 683 cases and 5 deaths in 2010, 226 cases and 1 death in 2011 and 223 cases and 4 deaths in 2013 representing $70 \%, 29.2 \%, 42.2 \%$ of the total of cases respectively (Benin Ministry of Health, 2010, 2011, 2012, 2013, 2014).

Hygiene and sanitation are important in the prevention of hydro-faecal diseases. Studies show that treatment of water and hand washing are factors that prevent the occurrence of Cholera in risky environments (Tanon et al., 2004; Dunkle et al., 2011). However, negative behaviours are still persisting (Schmidt et al. 2007; Scott et al., 2007a, 2007b). If programs of health promotion try to arouse changes in negative behaviours to prevent the disease, we can however wonder about their effectiveness. The counting of more than 500 articles on Education for Health in Developing Countries (DCs) allowed to list only three (3) showing satisfactory signs of a change in behaviour or an important impact on health (Curtis et al., 2001). For a risky behaviour to persist despite many campaigns, it must be influenced by many kinds of factors. These factors affect the adoption of new health-promoting behaviour or rooting of negative one.
The objective of this study was to investigate the factors associated to the behaviour of individuals with hygiene to prevent cholera disease in Vossa-Kpodji, a neighbourhood of Cotonou.

\section{MATERIALS AND METHODS}

It is a cross-sectional study for which target consisted of all 18 years or older inhabitants of Vossa-Kpodji.

\section{Sampling}

The sample size was determined using the Schwartz formula. We retained a proportion of $50 \%$ with a precision of $5 \%$; this gave us a minimum size equal to 384 . An increase of $6.25 \%$ was made and gave a final size of 408.

The Vossa-Kpodji neighbourhood of almost rectangular shape has been divided into five zones. We randomly selected zones 1, 3, and 5; and identified all the concessions in these areas. We used systematic random technique with a sampling interval equal to 2 to select the houses. Door to door, all willing adults aged 18 or older were interviewed regardless of gender.

\section{Study variables}

The PRECEDE / PROCEED model of Green (Renaud, 1999) was used to determine the explanatory variables of our study and identify factors associated to individuals behaviour in terms of hygiene. These factors are predisposing factors, facilitating factors and reinforcing factors (Figure 1). Predisposing factors, previous to the behaviour, corresponds to the factors that sustain motivation of behaviour. This includes knowledge, attitudes, beliefs, values, selfefficacy, behavioural intention, existing skills, demographic factors (socioeconomic status, age, gender, family size ...). Facilitating factors: also previous to the behaviour, they facilitate the achievement of a motivated action. Associated with the environment, they 
rely on the availability, the accessibility, the capacity to provide resources of health and community, the living conditions, the acquisition of new skills for behavioural or environmental change. Reinforcing factors: subsequent to the behaviour, they are reward or incentive to the behaviour and contribute to its maintenance, its repetition or discard if necessary. These factors include social support, peer influence, guidance and feedback from health professionals, the physical consequences of behaviour (pain or welfare) (Renaud, 1999). A number of facilitating and reinforcing factors are superimposable sometimes interchangeable.

Our dependent variable is the quality of hygiene practices towards the cholera. The independent variables are factors related to knowledge (knowledge of cholera by the population, knowledge of hygiene against cholera); socio-demographic factors (age, gender, ethnicity, religion, marital status, household type); factors related to socioeconomic status (income, education); environmental factors (availability of toilets or latrines, drinking water availability, proximity and abundance of dumps); factors related to the health system (use of health services); sociocultural factors (belief in the disease and the effectiveness of hygiene measures, peers influence).

Referring to the model of Green, knowledge of the cholera and prevention measures, the belief in the disease, the belief in the efficacy of preventive measures and socioeconomic status are predisposing factors. Environmental factors, use of health centres that will provide access to care and information related to cholera and other hydro-faecal disease risk are facilitating factors. The positive or negative influence of peers, their opinions and behaviour (social environment) are reinforcing factors of an action already taken. Environmental factors such as the proximity and abundance of dumps, the use of health services (for feedback from health professionals) can also be reinforcing factors (Figure 1). In our study, we investigated the relationship between the different factors and hygiene practices.

Fourteen (14) sub-variables were assessed for the evaluation of the hygiene practices. In each of them was attributed one (1) point in case of good practice and 0 when it was a bad practice. If the individual adds up 14 points, he/she has a good practice of hygiene towards the cholera. Less than 14 points is considered as having a bad practice in the environmental conditions of Vossakpodji in Cotonou.

Considering the criteria of knowledge of cholera, the individual has a good knowledge of cholera if he/she had responded to seven criteria (score $=7$ ). He/she has poor knowledge if he (she) meets less than 7 criteria (score less than 7). Considering the criteria of knowledge of hygiene measures, the individual has a poor knowledge if he (she) answers "no" to all criteria (score $=0$ ); he/she has a moderate knowledge if answers "yes" to a maximum of 7 criteria (score between 1 and 7); he/she has a good knowledge if he/she answers "yes" to more than 7 criteria. Considering the amount spent per month by individuals; those who spend less than 20.000 CFA francs per month were considered as having a low economic level; those reported spending more than 20.000 CFA francs per month have a good or acceptable economic level (Table 1).

\section{Data collection}

Data were collected using a questionnaire and an observation grid of the environment.

\section{Statistical analysis}

The data were checked, coded and analysed using Epi Info Version 6.04. Statistical analysis consisted in the calculation of frequencies for the description. The relationship between independent variables 
and dependent variable was tested using Khi2 test at a 5\% significance level.

\section{Ethical considerations}

Health authorities in the area have agreed. All participants gave their informed consent after being aware of the purpose of the investigation. Each household had a secret identifier and no names of investigated was kept.

\section{RESULTS}

\section{Predisposing factors}

On the 394 respondents who reported their age, $44.4 \%$ of them were between 26 and 40 years. The males were represented at $40 \%$. The majority of individuals were married $(81.86 \%)$. More than half $(68.1 \%)$ of respondents have a low level of education. A large proportion $(82.3 \%)$ of respondents has good or acceptable economic level based on the criteria that we have predetermined.

The majority of respondents $(92.6 \%)$ have a good knowledge of cholera. They were $78.7 \%$ to have a moderate knowledge of health measures to prevent cholera. By cons, less than a fifth of respondents $(18.1 \%)$ did not know the hygiene measures. In their majority, they believed in the existence of cholera $(95.2 \%)$ and the effectiveness of hygiene measures to prevent it $(92.5 \%)$ (Table1).

\section{Facilitating and reinforcing factors}

The majority of respondents $(92.4 \%)$ did not have a tap in their concession; $63.2 \%$ did not have latrines; $67.1 \%$ had a garbage dump near their homes. According to the respondents, $55.5 \%$ were not attending health centres of the district. It was estimated that $68.6 \%$ of the interviewees thought that their neighbours have bad hygiene behaviour that can increase the risk of cholera (Table 1).

\section{Hygiene practices}

People without adequate practices counted for the majority of the respondents that is $91.4 \%$ of the total. In our study, observation showed that there is a problem with the general hygiene in the neighbourhood. Indeed, garbage is stored anywhere with uncontrolled defecation. Many animals such as pigs, chickens and sheep are straying. Among respondents who have pets, $78.3 \%$ leave them to roam freely in their concession. This can increase the risk of proliferation of flies, contamination of soil, water and kitchen utensils and so increase the risk of cholera.

\section{Relationships between the characteristics of respondents and hygiene practices}

The proportion of individuals with poor hygiene practices (Table 2) was higher in single $(97.3 \%)$ than married $(90.2 \%)$. This difference is statistically significant $(\mathrm{p}=$ 0.04). Age, sex, religion, household type and level of education do not appear to be associated with poor hygiene practices. The proportion of individuals with bad practices was higher $(96.9 \%)$ for individuals with low socio-economic status $(\mathrm{p}=0.07)$. Individuals with poor hygiene practices were more prevalent among those who have little knowledge of cholera $(p=0.08)$. Among those who have little knowledge of hygiene measures, the proportion of poor hygiene practices is the highest (97.3\%). The difference was statistically significant $(\mathrm{p}=$ 0.03).

The proportion of poor hygiene practices is higher in individuals who did not believe in the existence of cholera and the effectiveness of hygiene measures. It is lower in those who thought that their relatives have poor hygiene practices $(88.8 \%)$ compared to those who did not $(95.1 \%)$. The difference was not statistically significant $(p=0.07)$. We observed a strong relationship between the availability of latrines and hygiene practices $(\mathrm{p}<0.0001)$. 
Predisposing factors:

-Knowledge of cholera and hygiene measures

-Belief in the disease and the effectiveness of

hygiene measures

-Sociodemographic and economic factors

\section{Facilitating factors: \\ -Environmental factors (availability of toilets or latrines, drinking water availability, proximity and abundance of dumps) \\ -Use of health services}

Behaviour: hygiene practice

\section{Reinforcing factors:}

Peer influence

Figure 1: Factors influencing the behaviour according to the PRECEDE/PROCEED model.

Table 1: Distribution of respondents according to hygiene practices, socio-demographic and economic characteristics, knowledge and beliefs vis-à-vis cholera and hygiene measures, environmental factors, attendance of health centres and peer influence.

\begin{tabular}{lcc}
\hline Variables & Number (n) & Percentage (\%) \\
\hline Hygiene practices & 408 & 91,4 \\
Good & & 8,6 \\
Poor & 394 & \\
\hline Age (years) & & 27,2 \\
$18-25$ & & 44,4 \\
$26-40$ & & 28,4 \\
$41-80$ & 408 & \\
\hline Gender & & 40 \\
Male & & 60 \\
Female & 406 & \\
\hline Ethnic group & & 53,7 \\
Fon & & 8,6 \\
Adja & & 7,6 \\
Goun & & \\
\hline
\end{tabular}




\begin{tabular}{|c|c|c|}
\hline Mina & & 6,7 \\
\hline Yoruba & & 5,9 \\
\hline Xwla & & 3,9 \\
\hline Toffin & & 3,2 \\
\hline Others & & 10,4 \\
\hline Religion & 396 & \\
\hline Christianity & & 86,9 \\
\hline Islam & & 4,3 \\
\hline Animism & & 5,1 \\
\hline Others & & 3,8 \\
\hline Marital status & 308 & \\
\hline Single & & 18,13 \\
\hline Married & & 81,86 \\
\hline Household type & 344 & \\
\hline Monogamous & & 67,9 \\
\hline Polygamous & & 32,03 \\
\hline Education level & 402 & \\
\hline Primary school & & 38,8 \\
\hline Secondary school & & 26,9 \\
\hline University & & 4,2 \\
\hline Unschooled & & 30,1 \\
\hline Economic level & 367 & \\
\hline Low & & 17,7 \\
\hline Good or acceptable & & 82,3 \\
\hline Knowledge of cholera & 408 & \\
\hline Poor & & 7,4 \\
\hline Bad & & 92,6 \\
\hline Knowledge of hygiene measures & 408 & \\
\hline Poor & & 18,1 \\
\hline Moderate & & 78,7 \\
\hline Good & & 3,2 \\
\hline Belief in the existence of cholera & 399 & \\
\hline No & & 4,8 \\
\hline Yes & & 95,2 \\
\hline $\begin{array}{l}\text { Belief in the effectiveness of hygiene } \\
\text { measures }\end{array}$ & 372 & \\
\hline No & & 7,5 \\
\hline Yes & & 92,5 \\
\hline Availability of tap water & 367 & \\
\hline Yes & & 7,6 \\
\hline No & & 92,4 \\
\hline Availability of latrines & 372 & \\
\hline Yes & & 36,8 \\
\hline
\end{tabular}




\begin{tabular}{lcc}
\hline No & 63,2 \\
\hline Proximity of dumps & 359 & 67,1 \\
Yes & & 32,9 \\
No & 380 & \\
\hline Frequent use of health services & 44,5 \\
Yes & & 55,5 \\
No & \multirow{2}{*}{326} & \\
\hline Perception of neighbours hygiene & & 68,7 \\
behaviours & & 31,3 \\
At risk of cholera & \\
Not at risk of cholera & \\
\hline
\end{tabular}

Table 2: Relationship between the independent variables studied and hygiene practices.

\begin{tabular}{|c|c|c|c|c|c|c|}
\hline \multirow{3}{*}{ Variables } & \multicolumn{4}{|c|}{ Hygiene practices } & \multirow{3}{*}{ Khi 2} & \multirow{3}{*}{$\mathbf{p}$} \\
\hline & \multicolumn{2}{|c|}{ Good } & \multicolumn{2}{|c|}{ Poor } & & \\
\hline & $\mathbf{N}$ & $\%$ & $\mathbf{N}$ & $\%$ & & \\
\hline \multicolumn{7}{|l|}{ Age (years) } \\
\hline $18-25$ & 7 & 6,5 & 100 & 93,5 & 3,13 & 0,20 \\
\hline $26-40$ & 20 & 11,4 & 155 & 88,6 & & \\
\hline $41-90$ & 7 & 6,3 & 105 & 93,8 & & \\
\hline \multicolumn{7}{|l|}{ Gender } \\
\hline male & 17 & 10,5 & 145 & 9,5 & 1,17 & 0,28 \\
\hline female & 18 & 7,4 & 225 & 92,6 & & \\
\hline \multicolumn{7}{|l|}{ Religion } \\
\hline Christianity & 31 & 9 & 313 & 91 & 2,21 & 0,53 \\
\hline Islam & 1 & 5,9 & 16 & 94,1 & & \\
\hline Animism & 0 & 0 & 20 & 100 & & \\
\hline Others & 1 & 6,7 & 14 & 93,3 & & \\
\hline \multicolumn{7}{|l|}{ Marital status } \\
\hline Single & 2 & 2,7 & 72 & 97,3 & 3,95 & 0,04 \\
\hline Married & 32 & 9,8 & 293 & 90,2 & & \\
\hline \multicolumn{7}{|l|}{ Household type } \\
\hline Monogamous & 24 & 10,5 & 204 & 89,5 & 1,43 & 0,23 \\
\hline Polygamous & 7 & 6,5 & 101 & 93,5 & & \\
\hline \multicolumn{7}{|l|}{ Education level } \\
\hline Primary school & 16 & 10,3 & 140 & 89,7 & 3,08 & 0,38 \\
\hline Secondary school & 8 & 7,4 & 100 & 92,6 & & \\
\hline University & 3 & 17,6 & 14 & 82,4 & & \\
\hline Unschooled & 8 & 6,6 & 113 & 93,4 & & \\
\hline \multicolumn{7}{|c|}{ Knowledge of cholera } \\
\hline Good & 0 & 0 & 30 & 100 & 3,04 & 0,08 \\
\hline Poor & 35 & 9,3 & 343 & 90,7 & & \\
\hline
\end{tabular}




\begin{tabular}{|c|c|c|c|c|c|c|}
\hline \multicolumn{5}{|c|}{ Knowledge of hygiene measures } & \multirow{3}{*}{6,98} & \multirow[b]{2}{*}{0,03} \\
\hline Poor & 2 & 2,7 & 72 & 97,3 & & \\
\hline Moderate & 30 & 9,3 & 291 & 90,7 & & \\
\hline Good & 3 & 23,1 & 10 & 76,9 & & \\
\hline \multicolumn{7}{|c|}{ Belief in the existence of cholera } \\
\hline No & 1 & 5,3 & 18 & 94,7 & 0,31 & 0,58 \\
\hline Yes & 34 & 8,9 & 346 & 91,1 & & \\
\hline \multicolumn{7}{|c|}{$\begin{array}{l}\text { Belief in the effectiveness of } \\
\text { hygiene measures }\end{array}$} \\
\hline No & 1 & 3,6 & 27 & 96,4 & 1,05 & 0,30 \\
\hline Yes & 32 & 9,3 & 312 & 90,7 & & \\
\hline \multicolumn{7}{|c|}{$\begin{array}{l}\text { Perception of neighbours hygiene } \\
\text { behaviours }\end{array}$} \\
\hline Not at risk of cholera & 5 & 4,9 & 97 & 95,1 & 3,29 & 0,07 \\
\hline At risk of cholera & 25 & 11,2 & 199 & 88,8 & & \\
\hline \multicolumn{7}{|l|}{ Economic level } \\
\hline Low & 2 & 3,1 & 63 & 96,9 & 3,16 & 0,07 \\
\hline Good or acceptable & 30 & 9,9 & 272 & 90,1 & & \\
\hline \multicolumn{7}{|c|}{ Frequent use of health services } \\
\hline No & 16 & 9,5 & 153 & 90,5 & 0,1 & 0,75 \\
\hline Yes & 18 & 8,5 & 193 & 91,5 & & \\
\hline \multicolumn{7}{|c|}{ Availability of tap water } \\
\hline No & 28 & 8,3 & 311 & 91,7 & 0,2 & 0,65 \\
\hline Yes & 3 & 10,7 & 25 & 89,3 & & \\
\hline \multicolumn{7}{|l|}{ Availability of latrines } \\
\hline No & 2 & 0,9 & 233 & 99,1 & 46,77 & 0,000 \\
\hline Yes & 29 & 21,2 & 108 & 78,8 & & \\
\hline \multicolumn{7}{|l|}{ Proximity of dumps } \\
\hline No & 7 & 5,9 & 111 & 94,1 & 1,35 & 0,24 \\
\hline Yes & 23 & 9,5 & 218 & 90,5 & & \\
\hline
\end{tabular}

\section{DISCUSSION}

\section{Hygiene practices}

The study showed that a large majority of respondents with poor food hygiene and body practices aimed to prevent cholera. This reflects the low level of hygiene towards cholera and other sanitation-related diseases.

The majority of respondents reported washing hands after defecation. However, Schmidt et al. (2007) in Kenya found that washing hands with soap and water only occurred in $24 \%$ of cases. In 2007, surveys conducted in Ghana found that only $3.5 \%$ of mothers washed their hands after defecation
(Scott et al., 2007a, 2007b). With regard to hand washing, our results could be explained by the fact that there is a good knowledge of the rules in Cotonou and in doing so, the respondents gave the answer that seemed to be the most appropriate to them without actually practice.

Our results showed that $46.5 \%$ of children under 5 defecate in the nature (garbage, bushes, lake, swamp,...); $72.3 \%$ of those with children under 5 years have thrown their features in nature; $60.2 \%$ of respondents do not cover their drinking water container. The observation had shown that there is an 
issue with the general hygiene in the neighbourhood. Garbage is stored anywhere with uncontrolled defecation. Many animals such as pigs, chickens and sheep are straying. This is a favourable environment for the occurrence of cholera. Similar hygiene issues were found by Badowsky et al. (2011). The fear of children falling in septic tank leads the parents to let them defecate freely in the concession. Though every family claimed storage of drinking water in covered containers, observation found several uncovered containers with standing water. Grey water is poured out into canals that flow into a neighbouring household or that drain to the streets behind the house. These results clearly show that regarding hygiene for the prevention of the cholera, it still remains room of improvement in our communities.

\section{Predisposing factors}

Demographic and economic characteristics

Our respondents were young with $44.4 \%$ who were between 26 and 40 years; and $27.2 \%$ who were between 18 and 26 years. It was found that $30.1 \%$ were not attending school against $38.8 \%$ who were at primary level. Scott et al. (2007b) found that more than half of their sample $(55 \%)$ did not reach the secondary level. This population of low education can have limitations in terms of understanding and perception of health phenomena. Nearly a quarter of respondents have a low socio-economic level. According to the results of Scott et al. (2007b), more than two thirds of the surveyed households had incomes below 55 US dollars (USD) per month. The difference with our results may be related to the assessment criteria that are the monthly expenses in our case and monthly income in the other criteria.
Level of knowledge of cholera and hygiene measures

Most of respondents have a good knowledge of cholera (92.6\%) and $78.7 \%$ have an average knowledge of hygiene measures. They were $15 \%$ of respondents who had already suffered of cholera and more than $50 \%$ of them have a relative who had suffered or had heard about it. In addition to that, the media seem to have an impact because $63.8 \%$ of the investigated had heard about it on radio. A study by Merten et al. (2013) in the Democratic Republic of the Congo showed that $96 \%$ of respondents knew the cholera; $44 \%$ have a family member who has suffered from it and $8 \%$ of respondents have been victims of. We can say that the level of education does not necessarily reflect the level of knowledge on health. Experience, influence of media and information campaigns are factors that may influence it.

\section{Beliefs related to cholera and preventive measures}

Over $90 \%$ of respondents believe in the existence of cholera and the effectiveness of hygiene measures. Merten et al. (2013) had found that $59 \%$ of respondents saw witchcraft as a cause of cholera. For $41 \%$ of respondents, cholera could be a consequence of the divine will. Dube et al. (2012) in Zimbabwe found that good hygienic practices can prevent the disease according to only $16.5 \%$ of respondents.

\section{Facilitating and reinforcing factors Environmental factors}

Among the respondents, $30 \%$ had a well in their backyard; but only one was using it as drinking water. For most of them, well water is dirty and unfit for consumption and in $98 \%$ of cases the water consumed was bought. Only $7.6 \%$ of respondents had an installation of running water. Guévart et al. (2006) in an assessment of the determinants of cholera in 
Douala in 2004 found that the distribution of drinking water was insufficient (32.5\%). Badowsky et al. (2011) found that on the 13 households, 06 used a public tap, 06 a private tap and 01 used a private well. All households bought water with a cost ranging from 4.38 to 31.29 USD per month.

According to our results, $36.8 \%$ of the respondents have latrines in their concession. This lack of coverage may be explained by the lack of allotment of the neighbourhood promoting temporary, anarchic and precarious constructions. In addition, the economic level of the population does not allow paying for the costs of the construction of latrines and emptying of septic tank. Bourre et al. (2001) found that in Haiti only $43 \%$ of the urban population has access to latrines. In Tanzania Badowski et al. (2011) also described the lack of proper latrines in the households surveyed. According to respondents, this is due to lack of financial means. The absence or inadequacy of sanitation seems to be a real problem in the Southern Countries.

\section{Social environment}

More than half of respondents $(68.6 \%)$ thought that the hygiene practices of those around them are at risk of the occurrence of cholera. Bad practices of the entourage could have a negative impact on individual and be a factor reinforcing behaviour. Social pressure or peer influence, however, could have a positive impact on the desired behaviour. Studies have demonstrated an increased frequency of hand washing when a health worker is observed by his peers (Pittet et al., 2000).

\section{Factors influencing bad hygiene practices Predisposing factors}

The only socio-demographic characteristic significantly associated with bad hygiene practices is marital status. The proportion of individuals with bad practices appeared to be higher among single than married. However, other factors have been highlighted in other studies. Awanou (2001) noticed that the level of education plays an important role in latrine use among people of the sub-district of Glazoué (Benin). In Ghana, Boadi et al. (2005) found that the level of maternal education has an influence on washing hands before preparing food and after using the toilet.

The proportion of individuals with bad hygiene practices is higher among those with a low level of knowledge of hygiene (97.3\%). The level of knowledge of hygiene is moderate at more than half of the individuals surveyed and is significantly related to hygiene practices $(\mathrm{p}=0.03)$. Djidonou (2000) found that the level of awareness of hygiene among school children of Zè (Benin) is moderate and can influence the practice. The level of knowledge of hygiene seems to be a predisposing factor that we could act on to obtain a modification of the bad behaviour. This assertion, however, is not supported by other studies. Indeed Badowski et al. (2011) retrieved that although most households are aware of the importance of hygiene measures, there is a discrepancy between their level of knowledge and practices that are at risk of developing hydro-faecal diseases.

These studies also confirm the fact that belief in the existence of cholera and the effectiveness of hygiene may not be related to malpractice. According to Curtis et al. (2009) the main motivations of hand washing are disgust, the level of care given to children, the feeling of comfort and social peer pressure. Fear of the disease usually does not motivate hand washing, except transiently in cases of epidemics such as cholera. These findings are reinforced by another study in which the main determinants of the practice of washing hands are the age of the child and the level of attention given by the mother to her child 
suggesting analytical elements for future studies (Scott et al., 2007b).

\section{Facilitating and reinforcing factors}

The presence of running water in the house is not related to bad hygiene practices in our study. Schmidt et al. (2009) found that access to water is associated with handwashing with soap and water. However, the presence or not of latrines in house is strongly associated to bad hygiene practices. The proportion of people with bad practices is higher with individuals who do not have latrines. Let us note however that $8.9 \%$ of those who have latrines do not use them; the reasons are the bad conditions of latrines; others prefer defecating in the nature. Awanou (2001) found that three quarters of respondents do not use latrines despite their availability. The reasons found are: poor maintenance of latrines, ignorance of the danger of hydro-faecal diseases.

Limitations of our study are that many respondents were aware of the good hygiene practices and may have given the answer that seems most appropriate. The observation nevertheless allowed us to detect the actual gaps in the practices of the respondents. The dependent variable is the composite of several sub-variables. The hygiene attitude and practices toward the common diarrheal diseases may differ from those toward cholera and could be a problem for comparability between studies.

\section{Conclusion}

Knowledge of hygiene may not be a factor that can motivate positive behaviour according to our results. With the advent of media and Communication Campaigns for Behaviour Change (CCC), information related to health is no longer the sole prerogative of school education. Although knowledge of hygiene is a factor that can motivate positive behaviour, other determinants such as disgust, the feeling of comfort, the level of care provided to children, social pressure are factors that could be taken into account in future studies. The existing link between the availability of latrines and hygiene practices is a significant determinant of the desired behaviour. The Department of Hygiene and Basic Sanitation of the Ministry of Health should assist people for achievement and sustainability of public and household latrines and develop a sanitation program that takes into account the peripheral areas of Cotonou.

\section{ACKNOWLEDGEMENTS}

The authors express their gratitude to the leaders of the Health Zone of Cotonou IV and the Borough of Vossa-Kpodji for their commitment to the realization of this work team.

\section{REFERENCES}

Awanou M. 2001. Analyse des facteurs liés à la non utilisation des latrines publiques dans la sous-préfecture de Glazoué. Mémoire de l'École Nationale des Assistants Sociaux, Université d'Abomey-Calavi, Faculté des Sciences de la Santé, Cotonou, Bénin, 56p.

Badowski N, Castro CM, Montgomery M Pickering AM, Mamuya S, Davis J. 2011. Understanding Household Behavioral Risk Factors for Diarrheal Disease in Dar es Salaam: A Photovoice Community Assessment. Journal of Environmental and Public Health, Article ID 130467, 10 p.

Boadi KO, Kuitunen M. 2005. Childhood diarrheal morbidity in the Accra Metropolitan Area, Ghana: socioeconomic, environmental and behavioral risk determinants. Journal of Health \& Population in Developing Countries /URL: http://www.jhpdc. unc.edu/. 
Bourre P, Joseph PF, Joseph PF, Gil REM. 2001. Haïti: la diarrhée aiguë est la première cause de mortalité infantile. Rev. Int. Pédiatr., 313: 9-12.

Curtis V, Danquah L, Aunger R. 2009. Planned, motivated and habitual hygiene behaviour: an eleven country review. Health Education Research, 24(4): 655-673.

Curtis V, Kanki B, Cousens S Diallo I, Kpozehouen A, Sangaré M, Nikiema M. . 2001. Signes d'évolution des comportements suite à un programme de promotion de l'hygiène au Burkina Faso. Bulletin de l'Organisation Mondiale de la Santé, 79(6): 518-527.

Djidonou NR. 2000. Connaissances et pratiques des écoliers de la souspréfecture de Zè en matière d'hygiène et d'assainissement. Mémoire de l'École Nationale des Assistants Sociaux, Université d'Abomey-Calavi, Faculté des Sciences de la Santé, Cotonou, Bénin, 57p.

Dube B, January J. 2012. Factors leading to poor water sanitation hygiene among primary school going children in Chitungwiza. Journal of Public Health in Africa, 3: 7.

Dunkle SE, Mba-Jonas A, Loharikar A, Fouché B, Peck M, Ayers T, Archer WR, De Rochars VM, Bender T, Moffett DB, Tappero JW, Dahourou G, Roels T, Quick R. 2011. Novembre Epidemic Cholera in a Crowded Urban Environment, Port-au-Prince, Haiti. Emerg Infect Dis., 17(11): 2143-2146.

Fattorousso V, Ritter O. 2004. Vademecum Clinique: du Diagnostic au Traitement (17 édn). Masson: Paris.

Guévart E, Noeske J, Solle J Essomba JM, Edjenguele M, Bita A, Mouangue A, Manga B. 2006. Déterminants du choléra à Douala. Méd. Trop., 66(3): 283-291.

Merten S, Schaetti C, Manianga C, Lapika B, Chaignat CL, Hutubessy R, Weiss MG. 2013. Local perceptions of cholera and anticipated vaccine acceptance in Katanga province, Democratic Republic of Congo. BMC Public Health, 13: 60.

Ministère de la Santé. 2010. Annuaire des statistiques sanitaires 2009. Direction de la programmation et de la prospective, Cotonou, Bénin.

Ministère de la Santé. 2011. Annuaire des statistiques sanitaires 2010. Direction de la programmation et de la prospective, Cotonou, Bénin.

Ministère de la Santé. 2012. Annuaire des statistiques sanitaires 2011. Direction de la programmation et de la prospective, Cotonou, Bénin.

Ministère de la Santé. 2013. Annuaire des statistiques sanitaires 2012. Direction de la programmation et de la prospective, Cotonou, Bénin.

Ministère de la santé. 2014. Annuaire des statistiques sanitaires 2013. Direction de la programmation et de la prospective, Cotonou, Bénin.

WHO. 2011. Juillet. Choléra, 2010. Relevé Épidémiologique Hebdomadaire, 31: 325-340.

WHO. 2014. Février. Choléra, aide-mémoire $\mathrm{N}^{\circ}$ 107. Centre des médias [on line] [Accessed at June 20th 2014]. Available at: http://www.who.int/ mediacentre/factsheets/fs107/fr/

Pittet D, Hugonnet S, Harbarth S et al. 2000. Effectiveness of a hospital wide programme to improve compliance with hand hygiene. The Lancet; 356: 1307-1312.

Renaud L. 1999. Planifier pour Mieux Agir (1è édn). REFIPS: Montréal. 
Schmidt WP, Aunger R, Coombes Y, Maina PM, Matiko CN, Biran A, Curtis V . 2009. Determinants of handwashing practices in Kenya: the role of media exposure, poverty and infrastructure. Tropical Medicine and International Health, 14(12): 1534-1541.

Scott B, Curtis V, Rabie T, Garbrah-Aidoo N. 2007a. Health in our hands, but not in our heads: understanding hygiene motivation in Ghana. Health Policy and Planning, 22(4): 225-233.

Scott BE, Lawson DW, Curtis V. 2007b. Hard to handle: understanding mothers' handwashing behaviour in Ghana. Health Policy and Planning, 22(4): 216-224.
Tabarly S. 2012. Choléra: géographie d'une pandémie. Étude de cas : Haïti, 2010 2012. Géoconfluences-DGESCO-ENS Lyon [on line], accessed at June 18th 2014, 10p. Available at: http://geoconfluences.ens-lyon.fr/doc/ transv/sante/SanteDoc3.htm

Tanon AK, Eholie SP, Ehui E CoulibalyDacoury C, Kra O, Kacou-N'douba A, Ekra D, Kakou A, Bissagnene E, Kadio A. 2004. Epidémie de choléra au CHU de Treichville (Abidjan) en 2001: aspects épidémiologiques, cliniques et thérapeutiques. Méd. Afr. Noire, 51: 559-566. 